\title{
The Health Related Quality of Life for Kidney Transplant Patients in Bulgaria-A Pilot Study
}

\section{Svetla Georgieva, Maria Kamusheva, Dragana Lakić, Konstantin Mitov, Alexandra Savova \& Guenka Petrova}

To cite this article: Svetla Georgieva, Maria Kamusheva, Dragana Lakić, Konstantin Mitov, Alexandra Savova \& Guenka Petrova (2012) The Health Related Quality of Life for Kidney Transplant Patients in Bulgaria-A Pilot Study, Biotechnology \& Biotechnological Equipment, 26:3, 3062-3065, DOI: 10.5504/BBEQ.2012.0005

To link to this article: https://doi.org/10.5504/BBEQ.2012.0005

$$
\text { (c) } 2012 \text { Taylor and Francis Group, LLC }
$$

\section{Published online: 16 Apr 2014.}

Submit your article to this journal $\sqsubset$

Llll Article views: 109

Citing articles: 1 View citing articles ๘ 


\title{
THE HEALTH RELATED QUALITY OF LIFE FOR KIDNEY TRANSPLANT PATIENTS IN BULGARIA - A PILOT STUDY
}

\author{
Svetla Georgieva ${ }^{1}$, Maria Kamusheva ${ }^{2}$, Dragana Lakić3 ${ }^{3}$ Konstantin Mitov $^{2}$, Alexandra Savova ${ }^{2}$, Guenka Petrova $^{2}$ \\ ${ }^{1}$ University Hospital "Alexandrovska", Pharmacy Department, Sofia, Bulgaria \\ ${ }^{2}$ Medical University - Sofia, Faculty of Pharmacy, Sofia, Bulgaria \\ ${ }^{3}$ Belgrade University, Faculty of Pharmacy, Belgrade, Serbia \\ Correspondence to: Guenka Petrova \\ E-mail: gpetrova@pharmfac.net
}

\begin{abstract}
The aim of the present study was to analyze the pharmacotherapy cost and quality of life of patents after kidney transplantation compared to those with chronic kidney disease in Bulgaria. This retrospective pharmacotherapy cost study and prospective health related quality of life (QoL) study was performed during 2010 - 2011 at the biggest Sofia hospital serving all transplant patients. The cost of pharmacotherapy was analyzed after reviewing patients' records. The health related quality of life was evaluated with the multi-attributable questionnaire SF-36, which measures 9 health domains.

Forty-two percent of the patients with chronic kidney disease, and $26 \%$ of those with kidney transplant were female. The average age of the transplanted patients was 39.7 for male patients and 42.2 for female ones, while in the group suffering from chronic kidney disease the average male age was 48.3 and that of female patients, 51.2. No statistically significant difference was observed among the mean monthly cost of therapy per patient during the two-year period. The QoL was with lower values in the role limitations domain for patients with chronic kidney diseases and this difference was statistically significant. We found a correlation among the mean cost of pharmacotherapy and mean QoL in both groups of patients. In the group of patients with kidney transplantation the place of living and general health state were positively correlated. The cost of pharmacotherapy and the health state in comparison with the previous year were also positively correlated.

This is the first Bulgarian study of the quality of life of kidney transplant patients. It shows that the SF-36 could be successfully used in this group of patients as well as for comparison with the QoL of patients with chronic kidney disease.
\end{abstract}

Biotechnol. \& Biotechnol. Eq. 2012, 26(3), 3062-3065

Keywords: kidney transplantation, quality of life, SF-36, pharmacoeconomics

\section{Introduction}

Health care has two ultimate goals, which are to prolong the life and to increase the quality of life. Measuring the health related quality of life gives important information about the health care progress. The chronic kidney disease affects more and more people in recent years and the need for transplantation increases (6). Worldwide there are 1.1 million patients registered in end-stage chronic kidney disease and their number increases with $7 \%$ per year. The prevalence of the disease is 135 per million inhabitants in Europe and 336 in the USA and increases permanently mainly as a result of diabetes progress. The survival after kidney transplantation is from $88 \%$ to $95 \%$ in the case when a dead or living donor is used, respectively (1). There are studies showing that the quality of life of patents with chronic kidney disease is severely hampered, but what happens after the kidney transplantation is relatively rarely studied (9).

The goal of our study was to analyze the cost of pharmacotherapy and quality of life of patents after kidney transplantation compared to those of patients with chronic kidney disease in Bulgaria.

\section{Materials and Methods}

A retrospective pharmacotherapy cost study and prospective health related quality of life study was performed during 2010 2011 at the biggest Sofia hospital serving all transplant patients. The cost of pharmacotherapy was analyzed after reviewing records of all patients with chronic kidney disease and kidney transplantation. Mean cost per month was calculated for both diagnoses.

The health related quality of life (QoL) was evaluated with the multidimensional questionnaire SF-36. The SF-36 is a self administered questionnaire containing 36 items. It measures health on eight multi-item dimensions covering physical functioning, role limitations, bodily pain, social functioning, general mental health, role limitations due to emotional problems, vitality, energy or fatigue, general health perceptions. There is also health state self evaluation in comparison with the previous year. For each dimension, item scores are coded, summed, and transformed on to a scale from 0 (worst health) to 100 (best health) (7). The SF-36 was previously used and validated for Bulgaria for patients with chronic kidney disease (9). Sixty-two transplant and 19 patients with chronic kidney diseases were interviewed.

Descriptive statistics, one way ANOVA analysis, Spearman correlation, and Kruskal-Wallis analysis were performed to evaluate the statistical significance of the differences in the QoL 
in different groups of patients with different characteristics, as well as the correlation among the patients' characteristics and QoL. For Kruskal-Wallis test the gender and age data were dichotomized.

\section{Results and Discussion}

\section{Pharmacotherapy cost}

All the studied patients with chronic kidney disease were on hemodialysis and their pharmacotherapy included antianemic and blood formulating medicines. After the transplantation the therapy comprises mostly of immunosuppressors (Table 1).

TABLE 1

Relative share of the prescribed medicines by INN*

\begin{tabular}{|l|c|c|c|c|}
\hline Condition & \multicolumn{2}{|c|}{ Year 2010 } & \multicolumn{2}{c|}{ Year 2011 } \\
\hline \multirow{4}{*}{$\begin{array}{l}\text { Chronic } \\
\text { kidney } \\
\text { disease }\end{array}$} & erythropoietin & $94 \%$ & erythropoietin & $86.70 \%$ \\
\cline { 2 - 5 } & calcitriol & $68.80 \%$ & calcitriol & $40 \%$ \\
\cline { 2 - 5 } & iron sucrose & $93.80 \%$ & iron sucrose & $87.50 \%$ \\
\hline \multirow{4}{*}{$\begin{array}{c}\text { Kidney } \\
\text { transplant }\end{array}$} & $\begin{array}{c}\text { azathioprine } \\
\text { mycophenolic } \\
\text { acid }\end{array}$ & $21 \%$ & azathioprine & $18,1 \%$ \\
\cline { 2 - 5 } & $\begin{array}{c}\text { everolimus } \\
\text { mycophenolate } \\
\text { mofetil }\end{array}$ & $1.60 \%$ & $\begin{array}{c}\text { mycophenolic } \\
\text { acid }\end{array}$ & $76.60 \%$ \\
\cline { 2 - 5 } & tacrolimus & $22.60 \%$ & tacrolimus & $1.60 \%$ \\
\cline { 2 - 5 } & sirolimus & $19.40 \%$ & sirolimus & $24.60 \%$ \\
\cline { 2 - 5 } & ciclosporin & $59.70 \%$ & ciclosporin & $57.40 \%$ \\
\hline
\end{tabular}

* INN: International nonproprietary names

No statistically significant difference was observed between the mean monthly cost of therapy per patient during the two years observed (Table 2).

TABLE 2

Mean monthly therapy cost (BGN)

\begin{tabular}{|l|c|c|c|}
\hline Condition & $\begin{array}{c}\text { Mean } \\
\text { monthly } \\
\text { therapy cost } \\
\mathbf{2 0 1 0}\end{array}$ & $\begin{array}{c}\text { Mean } \\
\text { monthly } \\
\text { therapy cost } \\
\mathbf{2 0 1 1}\end{array}$ & $\begin{array}{c}\text { One way } \\
\text { ANOVA } \\
\text { analysis } \\
\text { (P) }\end{array}$ \\
\hline $\begin{array}{l}\text { Kidney } \\
\text { transplant }\end{array}$ & 528.5557 & 445.3723 & 0.249136 \\
\hline $\begin{array}{l}\text { Chronic } \\
\text { kidney disease }\end{array}$ & 431.3271 & 420.8616 & 0.9626 \\
\hline
\end{tabular}

\section{Quality of life}

All observed patients were inquired with SF-36. Forty-two percent of the patients with chronic kidney disease and $26 \%$ of those with kidney transplant were female. The average age of the male transplanted patients was 39.7 and for the female ones, 42.2; while in the group with chronic kidney disease the average male age was 48.3 and that of the female patients, 51.2.
The QoL measured with the SF-36 was with lower values in the role limitations domain for patients with chronic kidney diseases (Fig. 1). This difference was statistically significant in comparison with transplant patients (ANOVA, $\mathrm{P}<0.05$ ) Table 3 and Table 4. It might be supposed that the necessity of frequent hemodialysis significantly limits the everyday life.

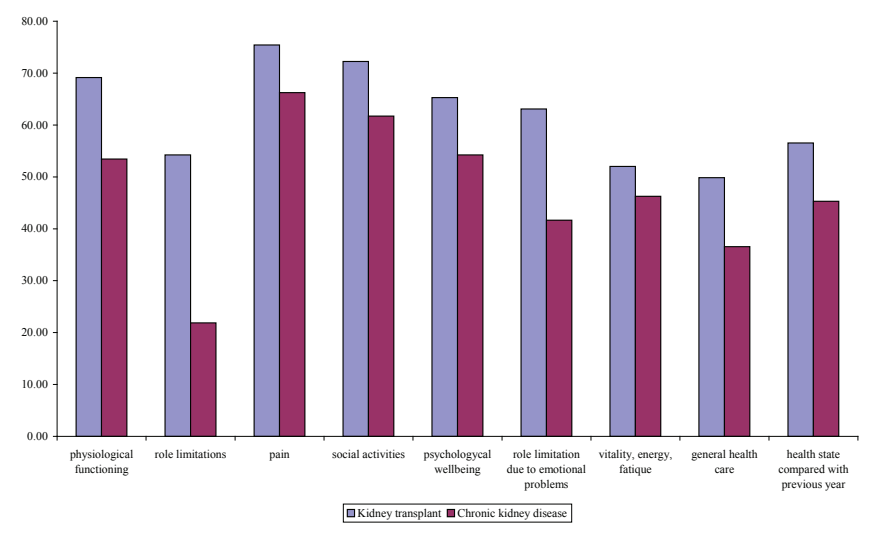

Fig. 1. Average value of SF-36 domains in the two groups.

TABLE 3

Descriptive statistics - kidney transplantation

\begin{tabular}{|l|r|r|r|r|}
\hline & Minimum & Maximum & Mean & $\begin{array}{r}\text { Standard } \\
\text { Deviation }\end{array}$ \\
\hline PhysFunc & .00 & 100.00 & 69.1354 & 31.71121 \\
\hline RoleLim & .00 & 100.00 & 55.0000 & 39.82383 \\
\hline Pain & .00 & 100.00 & 75.4308 & 26.58843 \\
\hline SocAct & 25.00 & 100.00 & 72.2308 & 20.90306 \\
\hline PsychHealth & 12.00 & 100.00 & 65.2938 & 18.83082 \\
\hline EmotProb & .00 & 100.00 & 63.0785 & 43.75135 \\
\hline VitEnFat & 20.00 & 75.00 & 52.0154 & 12.03315 \\
\hline GenerHealt & 5.00 & 100.00 & 49.8523 & 18.72696 \\
\hline HealthPrYear & 25.00 & 100.00 & 56.5385 & 17.82999 \\
\hline
\end{tabular}

TABLE 4

Descriptive statistics - chronic kidney disease

\begin{tabular}{|l|r|r|r|r|}
\hline & Minimum & Maximum & Mean & $\begin{array}{r}\text { Standard } \\
\text { Deviation }\end{array}$ \\
\hline PhysFunc & .00 & 100.00 & 56.9967 & 28.03885 \\
\hline RoleLim & .00 & 100.00 & 23.3333 & 38.34368 \\
\hline Pain & 32.50 & 100.00 & 70.6667 & 24.06217 \\
\hline SocAct & 25.00 & 100.00 & 65.8333 & 23.36944 \\
\hline PsychHealth & 24.00 & 92.00 & 57.8667 & 18.81438 \\
\hline EmotProb & .00 & 100.00 & 44.4333 & 43.03623 \\
\hline VitEnFat & 35.00 & 65.00 & 49.3333 & 7.76132 \\
\hline GenerHealt & 20.00 & 70.00 & 39.0000 & 14.41725 \\
\hline HealthPrYear & .00 & 75.00 & 48.3333 & 19.97022 \\
\hline
\end{tabular}


In both diagnoses the mean quality of life is lower than the maximum possible 100 points in all domains (Fig. 1). Patients with chronic kidney diseases are with lower QoL in all domains in comparison with transplanted patients. The differences in the quality of life are statistically significant (ANOVA, P = 0.0076). The higher mean values of the QoL in patients with kidney transplantation are probably due to the fact that the successful transplantations ensure normal life.

We found a correlation between the mean cost of pharmacotherapy and the mean QoL in the patients with kidney transplantation but not in the group with chronic kidney disease. The correlation is positive which means that the increase in the cost of pharmacotherapy should lead to increased QoL of patients (Table 5). The lack of correlation in the second group of patients could be commented with the final stage of the chronic kidney disease where little could be done to improve the quality of life.

TABLE 5 Correlation between the mean QoL and cost of pharmacotherapy

\begin{tabular}{|l|c|c|c|}
\hline Condition & Mean QoL & $\begin{array}{c}\text { Mean } \\
\text { monthly cost } \\
\text { of therapy in } \\
\text { 2011 (BGN) }\end{array}$ & $\begin{array}{c}\text { Spearman } \\
\text { correlation } \\
\text { coefficient }\end{array}$ \\
\hline $\begin{array}{l}\text { Kidney } \\
\text { transplant }\end{array}$ & 61.9784 & 445.37 & 0.298 \\
\hline $\begin{array}{l}\text { Chronic } \\
\text { kidney disease }\end{array}$ & 47.4788 & 420.86 & No \\
\hline
\end{tabular}

TABLE 6

Correlations within the groups of patients with kidney transplantation

\begin{tabular}{|l|c|}
\hline Correlated variables & $\begin{array}{c}\text { Spearman correlation } \\
\text { coefficient }\end{array}$ \\
\hline General health and place of living & $0.328(0.01 \mathrm{CL})$ \\
\hline $\begin{array}{l}\text { Cost of pharmacotherapy and } \\
\text { health state in comparison with the } \\
\text { previous year }\end{array}$ & $0.258(0.01 \mathrm{CL})$ \\
$0.302(0.01 \mathrm{CL})$
\end{tabular}

TABLE 7

Correlations within the group of patients with chronic kidney diseases

\begin{tabular}{|c|c|}
\hline Correlated variables & $\begin{array}{c}\text { Spearman correlation } \\
\text { coefficient }\end{array}$ \\
\hline $\begin{array}{c}\text { Cost of pharmacotherapy and } \\
\text { pain }\end{array}$ & 0.532 to $0.632(0.05 \mathrm{CL})$ \\
\hline $\begin{array}{c}\text { Cost of pharmacotherapy and } \\
\text { general health state }\end{array}$ & $0.515(0.05 \mathrm{CL})$ \\
\hline
\end{tabular}

The correlation between the characteristics of patients and particular domains of the QoL were further evaluated with
Spearman test (Table 6 and Table 7). In the group of patients with kidney transplantation the place of living and general health state were correlated positively and people living in the towns were shown to have better quality of life, probably due to the fact that they are closer to the health care services (Table 6). The cost of pharmacotherapy and health state in comparison with the previous year was also positively correlated, so with the increase of the cost the health care state self-evaluation improves.

In patients with chronic kidney disease the cost of pharmacotherapy and general health state were positively associated and the increase in the cost of therapy was found to benefit the patients' general health state evaluation, as well as to diminish the pain (Table 7).

The kidney transplantation is the only cure for chronic kidney disease. It aims to increase the patients' life expectancy through optimal kidney functioning. A variety of factors could influence the success of the transplantation and among them are the compatibility among the donor and recipient, immunological status, age, availability of infections, surgical complications, quality of life before the transplantation etc. (8). In this sense the studies of the quality of life of transplanted patients are important for the evaluation of the success of transplantation and its impact on the daily life (7).

After its development in 1980 the SF-36 became one of the most often used multidimensional instruments for QoL measurement $(3,5)$. The use of SF-36 in our study was also based on the previous experience gained with the patients with chronic kidney disease in Bulgaria (9). Our study confirmed the results of the previous one that the chronic kidney disease severely hampers the quality of life. It also confirmed the results of other studies that the psychological well-being is affected worst (2). Some new evidence is added for the significant influence of the transplantation on the QoL. In addition the study reveals that the access to health care and higher spending on pharmaceuticals also influences positively the QoL of transplant patients. The cost of therapy as an important QoL determinant was also confirmed (4).

Our study has some limitation as is the fact that it is not a long-term analysis but just a shot of the current state of the art. Further inquiries should be done to evaluate the long-term QoL after the transplantation.

\section{Conclusions}

This is the first Bulgarian study of the quality of life of kidney transplant patients. It shows that the SF- 36 could be successfully used in this group of patients as well as for comparison with the QoL of patients with chronic kidney disease.

\section{Acknowledgements}

This work was published with financial support from the "Human Resources Development" Operational Programme, "Science Business" Scheme (Grant № BG051PO001-3.3-05/0001). 


\section{REFERENCES}

1. Andrews P. (2002) BMJ, 324, 530, doi: 10.1136/ bmj.324.7336.530.

2. Boini S., Frimat L., Kessler M., Briançon S., Thilly N. (2011) Health and Quality of Life Outcomes, 9, 7.

3. Frybach D. et al., Health Measurement Research Group, Health-Related Quality of Life Measures, http:// www.healthmeasurement.org/Measures.html (Accessed: 15 Sept 2011)

4. Laupacis A., Keown P., Pus N., et al. (1996) Kidney International, 50(1), 235-242.

5. Healthy People 2020 (1 Dec. 2010) Health related Quality of Life and Well-Being, http://www.healthypeople. gov/2020/about/QoLWBabout.aspx (Accessed: 1-30 June 2011)
6. National Kidney Foundation (2007) Diabetes and chronic kidney disease, http://www.kidney.org/atoz/pdf/diabetes.pdf

7. McDowell I. (2006) Measuring health - A guide to rating scales and questionnaires, Oxford University Press, New York, pp. 100-250.

8. Paskalev E. (2003) Medical Review, 39(4), 68-71. (In Bulgarian)

9. Stefanov G. (2004) The quality of life of patients on periodic dialysis, $\mathrm{PhD}$ Thesis, Plovdiv, Bulgaria. (In Bulgarian) 